\title{
Functional Properties of Spherical Segments Made of Ti-Ni Alloy with Shape Memory Effect
}

\author{
A.B. Bondarev ${ }^{1}$, M.A. Khusainov ${ }^{2, a}$, V.A. Andreev ${ }^{1}$ \\ ${ }^{1}$ Industrial Centre MATEKS Ltd, Moscow \\ ${ }^{2}$ Yaroslav the Wise Novgorod State University, Velikiy Novgorod
}

\begin{abstract}
The article is devoted to the investigation of changing behavior of force parameters developing in the material of spherical (buckled) segments at heating, depending on the temperature of overheat and presence of strain concentrators. It is shown that overheats of spherical segments relatively to the temperature of reverse martensitic transformations $\left(\mathrm{A}_{\mathrm{f}}\right)$ up to $50,100,150,200,250 \ldots 600^{\circ} \mathrm{C}$ influence considerably the impact force and reactive forces. Specifically, the spherical segments exposed to overheat at temperatures in a free state always snap back with a stroke against the obstacle and with development of reactive forces at heating. Overheat of the spherical segments in a fixed state decreased the force parameters, and at annealing $\left(200-250{ }^{\circ} \mathrm{C}\right), 1 \mathrm{~h}$ the shape memory effect is suppressed completely. Influence of strain concentrators made up deliberately on the edges of the spherical segments depends on their length. It is shown that notches no more than $0,5 \mathrm{~mm}$ long do not influence the impact force and reactive force, while notches $\geq 1,0 \mathrm{~mm}$ long cause generation and development of nuclear cracks.
\end{abstract}

\section{Introduction}

It was found out experimentally [1-3] that spherical segments bent in martensitic state inversely to the initial shape snap back when heated to austenitic state, restoring the initial shape (the snap effect). The effect is observed if a spherical segment is free on edges. The segments supported or fixed on the edges do not snap. It is shown that abrupt recovery of the preset shape is caused by loss of stability of the object in the process of heating. The temperature of the loss of stability $\left(\mathrm{T}_{\mathrm{ls}}\right)$ at which the sample snaps back is near the finishing temperature of the reverse martensitic transformation $\left(\mathrm{A}_{\mathrm{f}}\right)$ and it depends on the correlation of geometrical parameters of the spherical segments $(D, R, h)$. Systematic research of the correlation of geometrical dimensions of the segments allowed to find their optimum relationships $[4,5]$ with which the stroke of maximum impact force is realized. Influence of the notches as stress concentrators was studied at the rate of changing of force parameters in the spherical segments. It is shown that with the increase in the notch length impact force $\left(\mathrm{P}_{\mathrm{imp}}\right)$ and reactive forces $\left(\mathrm{P}_{\mathrm{r}}\right)$ decrease correspondingly.

\section{Materials}

The research of mechanical behavior was conducted on spherical segments with the following dimensions: $D=$

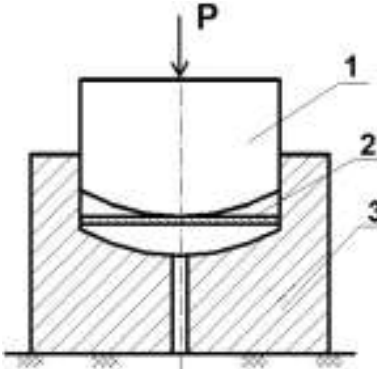

a)

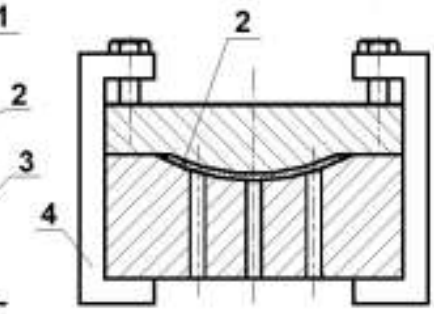

b)

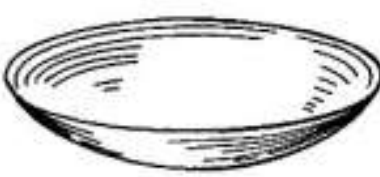

c)



d)

Fig. 1. Press mold for bending of a circular plate (a) and shape-setting at $420{ }^{\circ} \mathrm{C}, 1,5 \mathrm{~h}$ (b) in the form of the spherical segment (c) with geometrical parameters (d). 1- a punch; 2 - a circular plate; 3 - former block; 4 - clamps

${ }^{a}$ e-mail : vestnikenovsu.ru

This is an Open Access article distributed under the terms of the Creative Commons Attribution-Noncommercial License (http://creativecommons.org/licenses/by-nc/3.0/), which permits unrestricted use, distribution, and reproduction in any noncommercial medium, provided the original work is properly cited. 
$16,7-16,8 \mathrm{~mm}, h=0,43-0,46 \mathrm{~mm}, R=20,0-23,0$ $\mathrm{mm}$ made of $\mathrm{Ti}-50,3$ at $\% \mathrm{Ni}$ alloy with the temperatures of martensitic transformations: $\mathrm{M}_{\mathrm{s}}=$ $19^{\circ} \mathrm{C} ; \mathrm{M}_{\mathrm{f}}=8^{\circ} \mathrm{C} ; \mathrm{A}_{\mathrm{s}}=32^{\circ} \mathrm{C} ; \mathrm{A}_{\mathrm{f}}=44^{\circ} \mathrm{C}$, and alloy Ti- 50,0 at $\%$ Ni with the temperatures $\mathrm{M}_{\mathrm{s}}=42^{\circ} \mathrm{C}$, $\mathrm{M}_{\mathrm{f}}=20^{\circ} \mathrm{C}, \mathrm{A}_{\mathrm{s}}=56^{\circ} \mathrm{C}, \mathrm{A}_{\mathrm{f}}=78^{\circ} \mathrm{C}$.

The procedure of their production includes: production of circular plates $h=0,43-0,46 \mathrm{~mm}$ from cold rolled parent sheets. Subsequent spark cutting along the perimeter of a round master form formed the diameter of a round plate $(\varnothing=17 \mathrm{~mm})$. Next, the round plate was put in a press mold (Fig.1a) and bent by a spherical punch with a preset radius, rigidly fixed (Fig.1b) and annealed at $420^{\circ} \mathrm{C}, 1,5 \mathrm{~h}$ to set a shape. Made in such a way, the spherical (buckled) segment (Fig. $1 \mathrm{c}, \mathrm{d}$ ) after bending in martensitic state inversely to initial shape snaps with a clap when heated, restoring its initial shape. In the presence of an obstacle (Fig.3) the segment strikes against the body with a certain force $\left(\mathrm{P}_{\mathrm{imp}}\right)$. At further temperature rise reactive



Fig.2. The Temperature of loss of stability $T_{1 s}$ vs. a relative diameter $\mathrm{D} / \mathrm{R}$ of the spherical segments

$\mathrm{D} \times \mathrm{h} \times \mathrm{Ri}=17 \times 0,37 \times(32,28,26,23) \mathrm{mm}$. Alloy Ti$50,3 \mathrm{at} \% \mathrm{Ni}$

forces $\left(\mathrm{P}_{\mathrm{r}}\right)$ are generated in the material of the spherical segments reaching the peak value. It is noteworthy that the influence of the snap effect is observed only in the case the spherical segment is free on edges. The segments supported or fixed on the edges do not snap. It is shown that abrupt recovery of the preset shape is caused by loss of stability of the object in the process of heating. The temperature of the loss of stability $\left(\mathrm{T}_{\mathrm{ls}}\right)$ at which the sample snaps back is near the finishing temperature of the reverse martensitic transformation $\left(\mathrm{A}_{\mathrm{f}}\right)$ and it depends on the correlation of geometrical parameters of the spherical segments $(D, R, h)$. Fig.2 plots functional connection between $T_{1 s}$ and a relative diameter $(D / R)$.

It is seen that change of the radius of curvature of the segment $(\mathrm{R})$ displaces the temperature of the snap relative to $A_{f}$. It is found out by us that if strong snaps are realized then $T_{l s}>A_{f}$, if they are weak then $T_{1 s}<A_{f}$.

\section{Experimental}

Below a typical diagram of bending of the spherical segment in the martensitic state and shape recovery with a stroke at heating is presented (Fig.3). It is seen that the deforming force reaches the upper critical value $\left(\mathrm{P}_{u}\right)$, at which the effect of loss of stability is observed, as well as a weak clap and a sudden reduction of the active load



Fig.3. Diagram of bending of the spherical segment in martensite to the lower level of $\left(\mathrm{P}_{d}\right)$. Further loading till full-scale deflection occurs with the increase in the applied force to $\mathrm{P}_{\max }$. A small change in the deflection value is observed after unloading along DE. EM shows the elastic stage of the full-scale deflection of the segment. Now, if one starts heating from E, the sample restores its original shape (A), but the mode of shape recovery can be of two types. The first is a typical shape recovery which is initiated by oriented microstresses, originating from plastic deformation, the second is a sudden snapping back to the initial shape. The second type of the shape recovery under heating is realized only at certain ratio of dimensions of the spherical segment (diameter, thickness and radius of the curvature). Systematic experimental and theoretical research allowed to find their optimum relationship $[3,5,6]$ ensuring the snap effect with a clap in the presence of an obstacle (dynamometer). However it should be noted that the snap effect observed on spherical segments in the process of heating is realized only in case of easy running after loss of stability. If the shape recovery is forbidden in the area of loss of stability $(\mathrm{N})$, the effect is not realized. Only reactive stresses $\left(\mathrm{P}_{\mathrm{r}}\right)$ develop in the material of the segment. Consequently, easy running is an essential condition of snapping back, and to realize the stroke on the way of the return of the shape an obstacle in the form of a dynamometer is necessary (Fig.4). 


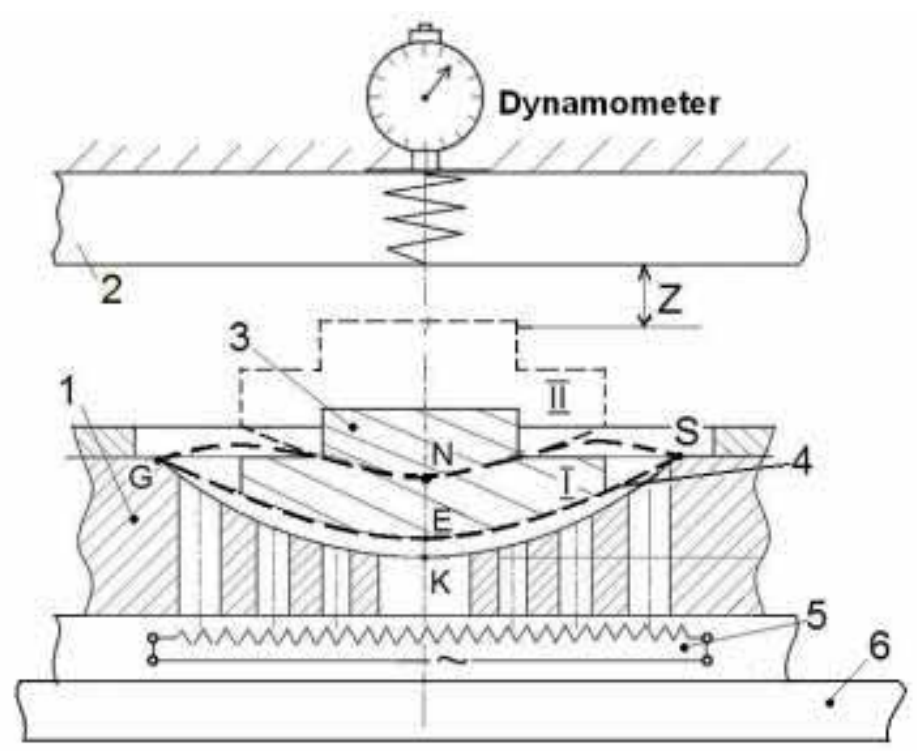

Fig. 4. A device to measure force parameters of a spherical segment. 1 - body; 2 - upper traverse of the tensile machine; 3 striker; 4 - neutral line of the segment after loading $(\mathrm{K})$ and unloading $(\mathrm{E})$; 5 - heater; 6 - lower traverse; I - initial and II final position of the punch $(\mathrm{N}) ; \mathrm{Z}$ - gap between the upper traverse 2 and side surface of the striker

This is illustrated by Fig. 3, 4. It is shown that if there is an obstacle in the domain of the loss of stability of the segment (point $\mathrm{N}$ ), shape recovery is partially suppressed. In the presence of easy running from $\mathrm{E}$ up to the obstacle (positions 1,2,3) impact forces increase to the maximum in proximity of $\mathrm{P}_{\mathrm{u}}$ (Fig. 3). Further increase in the length of the easy running to the positions 4,5 leads to the significant decrease in the impact force and reactive stresses.

It was shown experimentally on buckled segments of various sizes $\mathrm{D}, \mathrm{R}, \mathrm{h}$ (more than 100 samples) that snap effect is observed only at specific ratio of geometrical parameters. The main parameter as the research has shown is the radius of curvature. Fig. 5 presents a diagram of the bending with realization of the maximum impact force if the preset radius of curvature of the spherical segments is changed relative to the diameter $(\mathrm{D} / \mathrm{R})$.

It is seen that with the increase in the preset radius the level of impact force is decreased according to a linear law. The data is in accord with the theory [6], where it is shown that force parameters with the peak value are realized in the domain of optimum geometry, $\mathrm{D} / \mathrm{R}=0,74-0,76$, close to the separating border, when the spherical

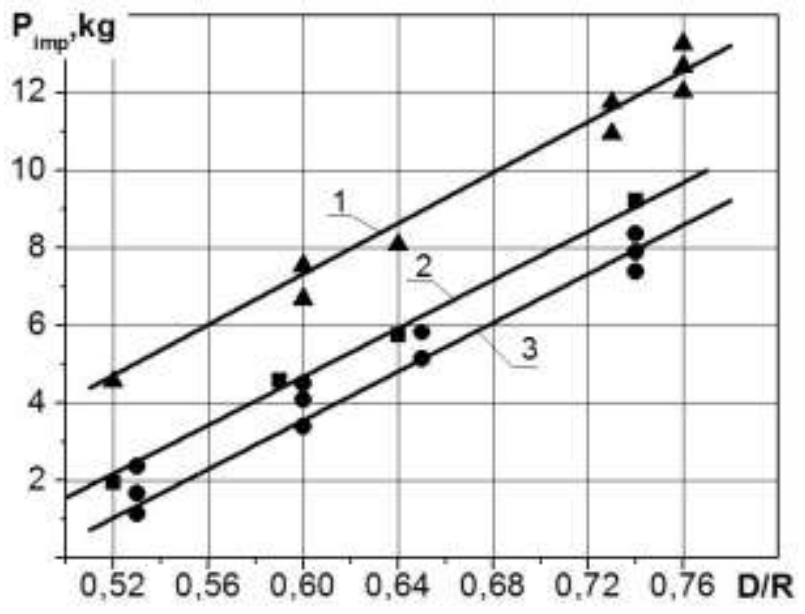

Fig.5. Impact force $\left(\mathrm{P}_{\text {imp }}\right)$ vs. a relative diameter of the spherical segment $(\mathrm{D} / \mathrm{R})$ after different types of preliminary heat treatment. 1 - annealing at $420^{\circ} \mathrm{C}, 1,5 \mathrm{~h} . \mathrm{D} \times \mathrm{h} \times \mathrm{R}_{\mathrm{i}}=16,8 \times$ $0,44 \times \mathrm{R}_{\mathrm{i}} \mathrm{mm} ; 2$ - annealing at $500^{\circ} \mathrm{C}, 0,5 \mathrm{~h} . \mathrm{D} \times \mathrm{h} \times \mathrm{R}_{\mathrm{i}}=16,7$ $\times 0,43 \times \mathrm{R}_{\mathrm{i}} \mathrm{mm} ; 3-$ annealing at $500^{\circ} \mathrm{C}, 0,5 \mathrm{~h} . \mathrm{D} \times \mathrm{h} \times \mathrm{R}_{\mathrm{i}}=17$ $\times 0,38 \times \mathrm{R}_{\mathrm{i}} \mathrm{mm}$ where $\mathrm{R}_{\mathrm{i}}=32,28,26,23,22 \mathrm{~mm}$. Alloy Ti$50,3 \mathrm{at} \% \mathrm{Ni}$ segment at heating is not able to pass through the middle plane (does not clap).

One of the main parameters of realization the snap effect and development of force parameters of the spherical segment is treatment, stabilizing alloy Ti-Ni texture. Based on research done in [7], heat treatment $420^{\circ} \mathrm{C}, 1,5 \mathrm{~h}$ combined with shape setting was chosen as the initial state of the objects under investigation.

Fig. 6a plots the curves of change in the impact force $\left(\mathrm{P}_{\mathrm{imp}}\right)$ and reactive forces $\left(\mathrm{P}_{\mathrm{r}}\right)$ of the spherical segments made of two alloys Ti-Ni after stabilizing annealing. It is seen that force parameters of the segments made of alloys enriched in nickel (Ti$50,3 \mathrm{at} \% \mathrm{Ni}$ ) are higher than equiatomic alloys. It is interesting to note that linear connection between the impact force and the diameter of the spherical segments of optimum geometry is of interest (Fig. 6b).This connection $P_{\text {imp }}$ vs. $D$ is hard to extrapolate on bigger diameters, since the experiments on segments $\mathrm{D}=40 \mathrm{~mm}$ have low statistics. 


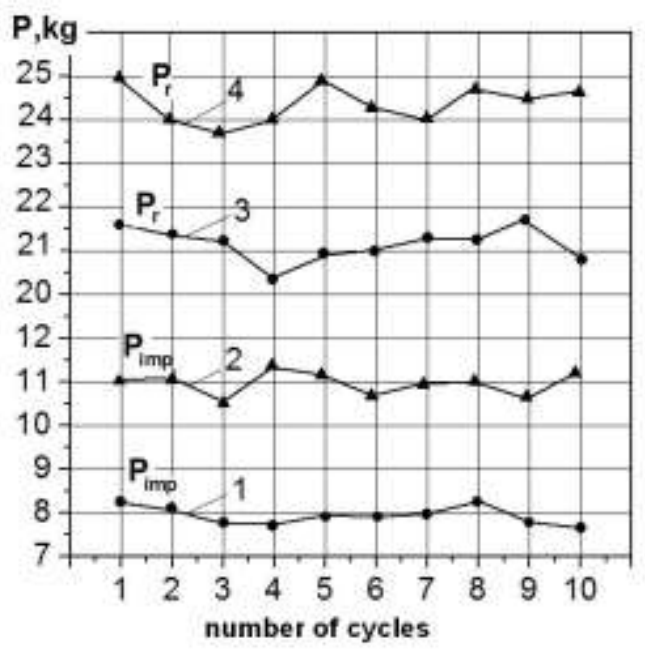

Fig.6a. Force parameters of the spherical segments after shape and memory setting at $420^{\circ} \mathrm{C}, 1,5 \mathrm{~h} .1,3$ - $\mathrm{D} \times \mathrm{h} \times \mathrm{R}=16,8 \times 0,45 \times 22 \mathrm{~mm}$, alloy Ti$50,0 \mathrm{at} \% \mathrm{Ni} ; 2,4-\mathrm{D} \times \mathrm{h} \times \mathrm{R}=16,7 \times 0,45 \times 22 \mathrm{~mm}$, alloy Ti- 50,3 at $\% \mathrm{Ni}$

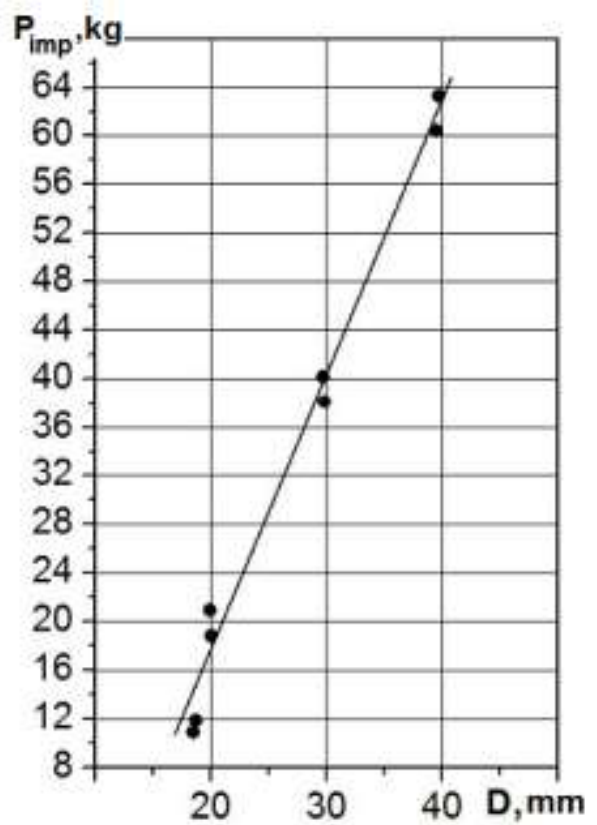

Fig. 6b. Connection between the impact force and the diameter of the spherical segments of optimum geometry.

There are many applications of spherical segments in engineering, for instance, in shutoff valves [8, 9]. In some valves (Fig.7) spherical segments are used as executive components closing the control port with an effort, developed in the material of the segment [10]. In others (Fig. 8) the spherical segment's stroke through the stem 2 to the lever 10, on which axis the eccentric cam is fixed, makes a sharp turn with the cam 13. As a result the power spring 12 becomes stable, pressing tightly the shutoff element $\mathbf{6}$ to the saddle of the valve. In this position the valve is closed.

Consistency of operation at a given temperature is one of the most important conditions of spherical segment reliability and operability. Possible overheat of the active elements (buckled segments) as a result of the temperature rise of the transportable liquid can cause considerable decrease in the level of forces developing in the material and reactive stresses. Simultaneously operation temperatures change in accordance with the kinetics of generation and relaxation of the reactive forces. It results in destabilization of the running regime of the shutoff element or of the whole valve. In this area of study much research remains to be done. It is of great interest to investigate the impact of strain concentrators on the edges of the spherical segments in consequence of electro spark cutting of the segments on the outlines.

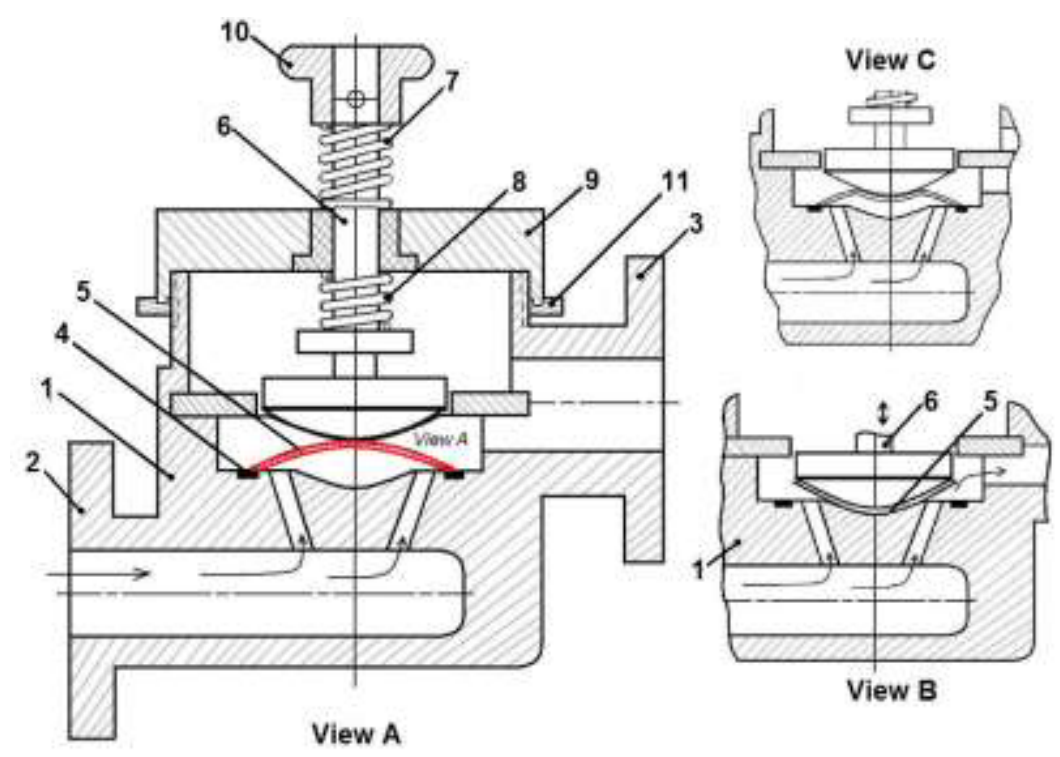

Fig. 7. The shutoff valve in section (View A). View B - opened position.

1-frame; 2 - inlet fitting; 3 - outlet fitting; 4 - saddle; 5 - shutoff valve with an active shape memory element; 6 - pushing rod; 7, 8 - springs; 9 - valve cover; 10 - pressure exerting body; 11- lock-nut. 
Below experimentally obtained data is presented on influence of overheat and notches on force parameters $\left(\mathrm{P}_{\text {imp }}, \mathrm{P}_{\mathrm{r}}\right)$ of spherical segments. Overheats of the spherical segments were conducted in the furnace in fixed and free states. Fig. 9 presents the data on the influence of the holding time at preset temperature of overheat $50^{\circ} \mathrm{C}$, i.e. annealing at $100^{\circ} \mathrm{C}$. It is seen that with the increase in the holding time at preset temperature force parameters of the spherical segments increase. This type of behavior can be divided into two stages. At the first stage the growth rate of force parameters of the segment constantly decreases. Duration of this period is 20-30 min. The second stage processes at low speed. Unstable behavior of the alloy at the first stage is believed to be caused by non-equilibrium state of the alloy texture. Taking this fact into consideration while conducting new experiments, the holding time was $60 \mathrm{~min}$. Fig. 10 demonstrates the impact force vs. the temperature of annealing, it shows how $\mathrm{P}_{\mathrm{imp}}$ of the spherical segments made of $\mathrm{Ti}-\mathrm{Ni}$ with shape memory effect changes.

It is seen that for alloys of equiatomic composition and enriched in nickel there exist a regular connection. Force parameters of spherical segments made of the mentioned alloys are close to their values and change in accordance with one law. However the following differences should be born in mind. First of all, segments of alloy $\mathrm{Ti}-50,3$ at $\% \mathrm{Ni}$ differ from atomic in more powerful impact force in all intervals of overheat. Secondly, they snap back with a clap even after annealing at $600 \mathrm{C}$, whereas segments made of alloy Ti- 50,0 at $\% \mathrm{Ni}$ do not snap back even after annealing at $500^{\circ} \mathrm{C}$. High level of force parameters of spherical segments is explained by the effect of ageing, caused by precipitation of microatomized proeutectoid constituents of the type $\mathrm{Ti}_{3} \mathrm{Ni}_{4}, \mathrm{Ti}_{2} \mathrm{Ni}_{3}$ и $\mathrm{Ti}_{2} \mathrm{Ni}_{3}$ [11], strengthening the alloy at

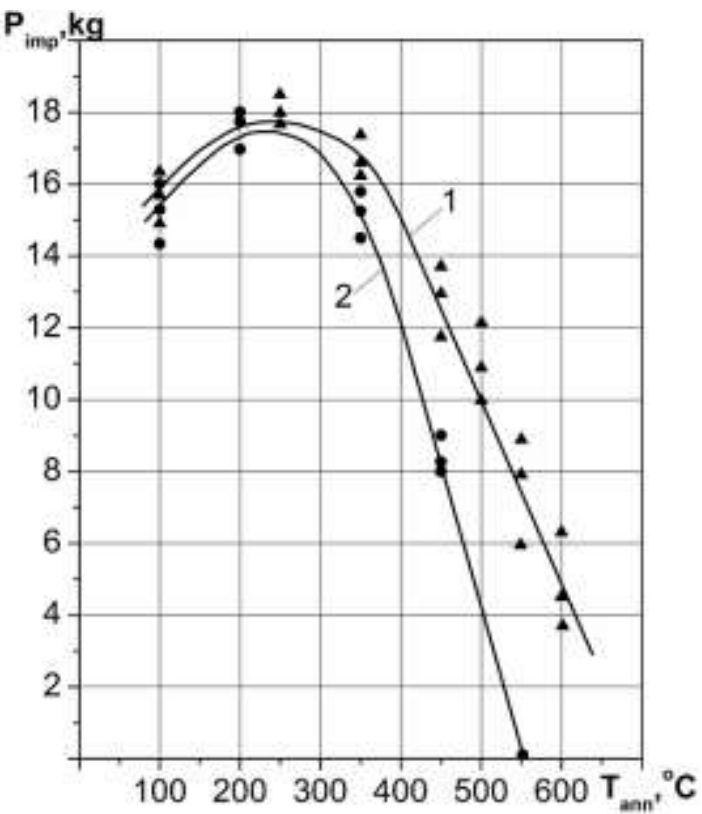

Fig. 10. Influence of overheats on the impact force of the spherical segments. $\left(\mathrm{T}_{\mathrm{oh}}=\mathrm{T}_{\mathrm{ann}}-\mathrm{A}_{\mathrm{f}}\right) .1$ - Alloy Ti-50,3at $\%$ $\mathrm{Ni}$; Af $=46-52^{\circ} \mathrm{C} ; 2$ - Alloy Ti-50,0at $\% \mathrm{Ni}$; Af $=77-$ $81^{\circ} \mathrm{C} ; \mathrm{D} \times \mathrm{h} \times \mathrm{R}=(16,6 \div 16,8) \times(0,45 \div 0,48) \times(22 \div 23)$ $\mathrm{mm}$

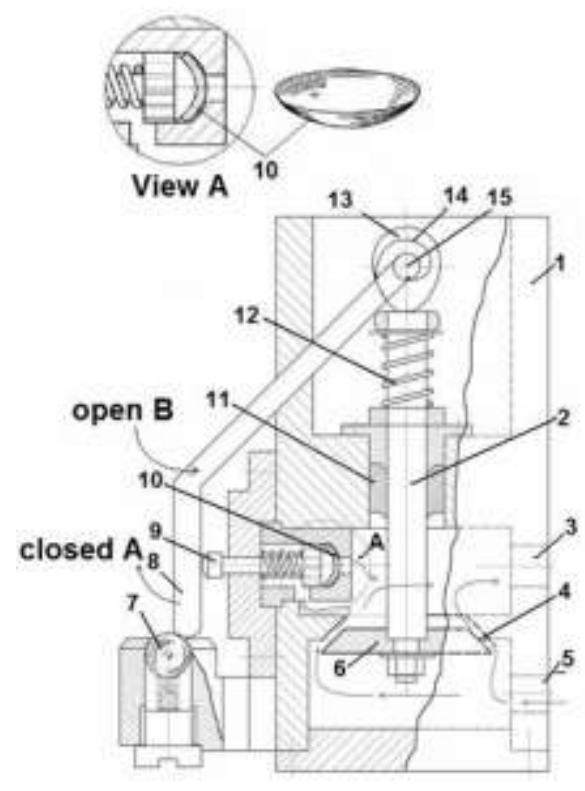

Fig. 8. General view of the shutoff valve in section. 1- frame; 2 - stem; 3 - hole for liquid removal; 4 saddle; 5 - coolant inlet; 6 - shutoff element; 7 fixator; 8 - lever; 9 - pusher; 10 - spherical segment; 11 - gland; 12 - power spring; 13 - eccentric cam; 14 -

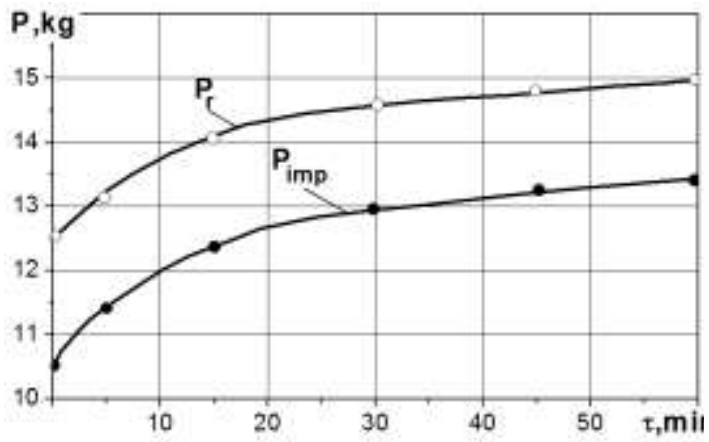

Fig. 9. Influence of the holding time at $100^{\circ} \mathrm{C}$ on force parameters of the spherical segments. $\mathrm{D}=19,8 \mathrm{~mm} ; \mathrm{h}$ $=0,46 \mathrm{~mm} ; \mathrm{R}=28 \mathrm{~mm}$. Alloy Ti- 50,3 at $\% \mathrm{Ni}$.

annealing $\left(>300^{\circ} \mathrm{C}\right)$. Probable cause of decline of force parameters of equiatomic alloy $\mathrm{Ti}-\mathrm{Ni}$ at higher temperatures at annealing is relaxation of elastic stresses and development of recrystallized processes.

Overheats of the segments in a fixed state at 200$250^{\circ} \mathrm{C}$ suppress shape memory effect. The spherical segments after the treatment do not snap back. The alloy hardening and decrease in the shape recovery effect is observed.

Influence of the notches on the form changing of the spherical segments under multiple recycling bend in martensite $\leftrightarrow$ heat to austenite (in a free state) was investigated in $[2,5]$. In this paper mostly systematized results of the research on influence of the incisions on force parameters $\left(\mathrm{P}_{\mathrm{imp}}\right.$ and $\left.\mathrm{P}_{\mathrm{r}}\right)$ generating in the material of the objects under heating are represented. 

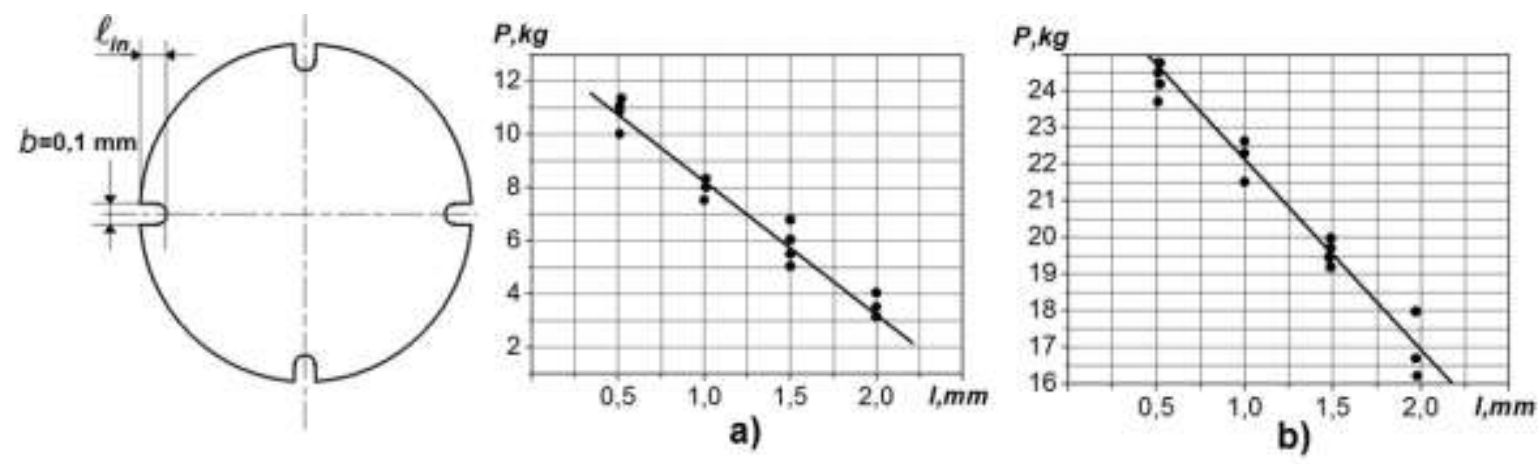

Fig. 11. Force parameters of the spherical segments vs. the length of the notch. $a-\operatorname{Impact}$ force $\left(P_{i m p}\right) ; b-$ reactive forces $\left(P_{r}\right)$

Analysis of stress condition of convex segments shows that their edges are most sensitive to concentrators of elastic stresses. It is proved by the appearance of microcracks on the edges of the segments at cycling of the segments in unrestrained condition according to the scheme [11] after $10^{4}$ cycles. Fig.11 shows the dependence of the notch length on the impact force and reactive forces. It is demonstrated that force parameters generating in the spherical segment material at heating decreased with the increase of the notch length. The evidence obtained shows that the size of the strain concentrators influences reactive forces. The data should be taken into account when designing shutoff valves with the use of spherical segments. It should be noted however that the stress is distributed unequally at the top of the notch [12]. As a result, several microcracks were formed simultaneously mostly from one notch, though there are four other notches located diametrically.

Later, after dozens of cycles with the realization of the stroke and reactive forces the first microcrack developed further. Repetition of the cycles segment bend in martensite $\leftrightarrow$ heating to $\mathrm{A}_{\mathrm{f}}+15^{\circ} \mathrm{C}$ with a stroke and development of reactive forces causes the extension of the crack the form of the wedge directed to the dome of the segment (Fig. 12). Being 0,07-0,08 $\mathrm{mm}$ long from any notch, the crack does not grow for some time. This can be attributed to the stability of the force parameters, since their value was the same during 5-10 following cycles. Further the crack expanded up to $\geq 0,3 \mathrm{~mm}$ and the snap effect was not realized. A typical shape recovery is observed as a consequence of the shape memory effect.

\section{CONCLUSIONS}

1. A method of studying of generation of reactive forces in the material of spherical segments bent in martensite inversely to initial shape at heating is worked out.

2. Influence of overheat relative to $A_{f}$ is investigated. A critical temperature of overheat $\left(400^{\circ} \mathrm{C}\right)$ was set, above which the snap effect of the alloys made of Ti-50,3 at $\% \mathrm{Ni}$ occurs with a weak clap, and with the alloys made of Ti- 50,3 at $\% \mathrm{Ni}$ the snap effect is suppressed.

3. High susceptibility of the spherical segments to notches is shown. A linear connection between forces generating in the material and the length of the incision is revealed.

4. Peculiarities of crack generation and development are examined. Critical sizes of the cracks excluding the effect of deformation jump with a snap observed on spherical segments deformed in martensite in the process of warming are described.

Fig. 12. A typical view of the crack generation (a) and development (b) 


\section{References}

[1] Khusainov M.A., Letenkov O.V., Pazgalov A.F., Belykov V.N. Research of TiNi Membrane Stability Materials with Complex Functional-mechanical Properties, Computer Aided Design of Materials. Novgorod, 1994. p. 152-158.

[2] Khusainov M.A., Malukhina O.A., Belykov V.N., Letenkov O.V. Investigalion of Resistance of Alloy Spherical Sheaths with Shape Memory Effect (SME) Proceedings of the Second International Conference on Shape Memory and Superelastic Technologies (SMST-97). USA, California, Alisomar Conference Centre Pasifik Grove. 2006. March 1997. p. 215-219.

[3] M.A. Khusainov J. Theor. Phys., vol. 67, № 6 1997, P.118-120.

[4] Popov S.A., Khusainov M.A., Bondarev A.B., Andreev V.A. Modeling of Snap Effect of Shape Memory Convex Segments// Vestnik NovSU. Ser.: Engineering Sciences 2005. №34. P. 12-16.

[5] Khusainov M.A. TiNi shape memory alloys. Structure, Phase Transformations and Properties / edited by V.G.Pushin. Yekaterinburg, vol.1, 2006, p. 226-242.

[6] Popov S.A., Khusainov M.A., Bondarev A.B., Andreev V.A. Optimization of Geometric Parameters of TiNi Shape Memory Convex Segments Vestnik NovSU. Ser.: Engineering Sciences, 2006, №39, p. 28-30.

[7] Khusainov M.A., Bondarev A.B., Begunov A.A., Letenkov O.V. Influence of Various Kinds of TMT on the Snap Effect of the Spherical Segments, Proceedings of the International Conference on Problems of Solidity. Belarus, Vytebsk, 2007, p. 294-295

[8] Khusainov M.A. Patent RF № 2182272 from 10.05.02, Shutoff Valve, Bull № 7.

[9] Khusainov M.A., Tambulatov B.Ya., Larionov A.G., Malukhina O.A. Patent RF № 2171937 from 10.08.01, Termo-valve, Bull № 22.

[10] Khusainov M.A., Bondarev D.A., Maslenkov D.A., Andreev V.A. A Cut-Off Thermo-Valve, International Conference and Exhibition on New Actuators and Drive Systems. Conference Proceedings 9-11 June 2008. Bremen, Germany, 2008, p. 895-897.

[11] Zhuravlev V.N., Pushin V.G., Alloys with Thermo-Mechanical Memory and Their Application in Medicine. Ekaterinburg, 2000, p. 77-85

[12] Ekorobi T. , Physics and Mechanics of Failure and Solidity of Solids. Moscow, 1971, p.141-149. 